\title{
Landscape genetics of the self-compatible forest herb Geum urbanum: effects of habitat age, fragmentation and local environment
}

\author{
K. VANDEPITTE, ${ }^{*}$ H. JACQUEMYN,† I. ROLDÁN-RUIZ and O. HONNAY* \\ *Laboratory of Plant Ecology, Biology Department, University of Leuven, Kasteelpark Arenberg 31, B-3001 Heverlee, Belgium, \\ †Division of Forest, Nature and Landscape Research, University of Leuven, Celestijnenlaan 200 E, B-3001 Leuven, Belgium, łUnit \\ Plant, Institute for Agricultural and Fisheries Research ILVO, Caritasstraat 21, B-9090 Melle, Belgium
}

\begin{abstract}
To investigate the role of habitat fragmentation, fragment age and local environment in shaping the genetics of plant populations, we examined the genetic structure of the selfcompatible forest herb Geum urbanum using microsatellite markers. A historical land-use reconstruction assigned the studied populations to two age classes: populations in primary forest fragments, and populations in secondary fragments. Local environmental conditions were quantified on the basis of the herb-layer community composition. A stepwise general linear model revealed that levels of within-population genetic diversity were best explained by population size, landscape connectivity and the interaction between both. Connectivity was positively correlated with the genetic diversity of small populations, but did not significantly affect the diversity of large populations. Contrary to what we expected, secondary-forest populations showed lower divergence relative to populations located in primary patches. Small populations were genetically more diverged compared to large populations. Mantel tests showed no significant isolation by distance and no significant correlation between habitat similarity and genetic differentiation. We conclude that gene flow has probably prevented founder events from being reflected in the present genetic structure of G. urbanum. Gene flow towards low-connectivity populations, however, seemed to be insufficient to counteract the effects of drift in small populations.
\end{abstract}

Keywords: forest age, Geum urbanum, habitat fragmentation, landscape connectivity, local environment, SSR

Received 20 February 2007; revision received 22 April 2007; accepted 11 June 2007

\section{Introduction}

The genetic diversity maintained within a group of organisms is a function of historical and recent evolutionary processes (Godt et al. 1996). Genetic drift, gene flow, inbreeding, natural selection and mutation shape the genetic structure and magnitude of genetic variation among and within populations (Barrett \& Kohn 1991; Slatkin 1993). Landscape genetics has emerged as a new research area that integrates population genetics, landscape ecology and spatial statistics to explain how landscape characteristics shape population genetics (Manel et al. 2003; Storfer et al. 2007).

Correspondence: Katrien Vandepitte, Fax: +32 (0)92722901; E-mail: katrien.vandepitte@ilvo.vlaanderen.be
In dynamic landscapes, where habitat fragments differ in age, an equilibrium between rates of gene flow and genetic drift is rarely achieved and founding events may play a significant role in the determination of plant population genetic variation. Classical metapopulation models predict that the origin of colonists and the degree of migration after colonization determine genetic divergence between populations (McCauley 1991; McCauley et al. 1995). Slatkin (1977) investigated this issue with two variations of Wright's (1931) basic island model. In the 'propagule pool' model, all individuals that comprised a given founding group were drawn from the same source populations. In combination with low gene flow rates, small founding groups from limited sources allowed newly founded populations to genetically diverge through drift and inbreeding. In the 'migrant pool' model, colonists were randomly drawn from 
different pools. The mixing of different genotypes tore down genetic structure and genetic divergence became lower than that under the expectations of the basic island model (Wright 1931). Whitlock \& McCauley (1990) theoretically demonstrated that cycles of extinction and recolonization will increase between-population genetic differentiation and decrease the genetic variation within newly founded populations if colonists are drawn from a relatively limited number of populations and subsequent migration rates are in the same range as colonization rates.

In a highly fragmented landscape, the colonization of newly created habitats by a given species will be strongly influenced by both landscape connectivity and population size. These factors have also an important effect on the population genetic structure of the populations. In the first place, the probability of dispersal to, and colonization of a target fragment is mainly determined by its connectivity to extant populations (Hanski 1998). In plant species, the resulting genetic structure of fragmented populations may be further complicated by gene flow through pollen (McCauley 1994) and by the breeding system (Hamrick \& Godt 1996). As spatial isolation limits gene flow among populations, it will contribute to higher levels of differentiation between populations (Young et al. 1996). Population size will have a similar effect on the within-population genetic diversity. As in the absence of gene-inflow, the number of alleles of small populations will decrease through genetic drift, with rarer alleles having the highest risk (Barrett \& Kohn 1991; Ellstrand \& Elam 1993; Young et al. 1996). In addition, genetic variability is expected to decrease further in small populations as a result of increased selfing and biparental inbreeding, both of which increase the level of homozygosity (Ellstrand \& Elam 1993). In the short term, decreased genetic variability may increase the expression and accumulation of mildly deleterious alleles (Ellstrand \& Elam 1993; Young et al. 1996; Keller \& Waller 2002). In the long term, decreased genetic variability can limit a species' ability to respond to different selection pressures (Barrett \& Kohn 1991; Young et al. 1996) because levels of quantitative genetic variation necessary for adaptive evolution erode (Keller \& Waller 2002).

The predicted consequences of habitat fragmentation and founder events on plant population genetics have only rarely been tested empirically (see, e.g. Giles \& Goudet 1997; Jacquemyn et al. 2004, 2006; Vellend 2004). The distribution of forest herbs in fragmented forest landscapes offers a unique opportunity to investigate the role of landscape configuration and forest fragment age in shaping the genetic diversity and structure of fragmented plant populations. In most European countries, the tree layers are generally planted at the time of agricultural abandonment while the herb layer is left to spontaneous development. As not all forest fragments have been planted simultaneously, European fragmented forest landscapes generally consist of a mixture of fragments of different ages. This mosaic of fragments of different ages results in a population age structure of the herb layer, which can readily be assessed by the age of the forest patches (Jacquemyn et al. 2004).

In addition to fragmentation and forest age, local habitat conditions may also affect genetic diversity and divergence of plant populations. Several studies have provided evidence that environmental or habitat variability has the potential to influence the partitioning of genetic variation within and among populations (Antonovics 1971; Gram \& Sork 2001). Local selection processes (Hamrick \& Allard 1972; Zangerl \& Bazzaz 1984; Owuor et al. 1999; Hall \& Willis 2006), and reduced seedling recruitment in lesssuitable habitats (Jacquemyn et al. 2005) are environmentmediated processes that shape the genetics of plant populations.

We studied the population genetic structure of $18 \mathrm{Geum}$ urbanum (Woody avens) populations in a highly fragmented forest landscape in Belgium. Geum urbanum is a relatively common forest herb with a mainly selfing mating system (Taylor 1997). The study area has been subjected to vast deforestation and a considerable forest turnover rate during the last 200 years (Jacquemyn et al. 2001a, b, 2003). Given that the studied forest plant populations are relatively isolated in a hostile matrix, we predicted that the colonization of newly created habitat patches is affected in most cases by propagules driven from a limited number of sources and that subsequent gene flow is also very limited. As a consequence, the level of genetic differentiation among recently founded populations in secondary forest fragments should be high, compared to populations located in primary patches. Similarly, we expected secondary forest populations to display lower levels of diversity than populations in primary patches.

We specifically addressed the following questions:

1 Does habitat fragmentation (in terms of landscape configuration and population size) affect the genetics of the studied G. urbanum populations?

2 Have differences in fragment age resulted in higher levels of genetic differentiation and in lower genetic variation within secondary forest compared to populations in primary forest fragments?

3 Does local environment affect the genetics of the studied populations?

\section{Materials and methods}

\section{Study species}

Geum urbanum (Rosaceae) is widespread and abundant throughout its distribution range, which comprises most of Europe, western Asia, western Siberia, the Himalaya 
Table 1 Fragment age, population size, local environment and genetic diversity measures within populations of Geum urbanum and means over all populations

\begin{tabular}{|c|c|c|c|c|c|c|c|c|c|}
\hline ID & Size & Age & Conn & Env & $n$ & $P L P$ & $A_{\mathrm{R}}$ & $H_{\mathrm{O}}$ & $F_{\text {IS }}$ \\
\hline 1 & 2 & $S$ & 3.09 & 189.18 & 20 & 50 & 1.97 & 0.017 & 0.944 \\
\hline 2 & 1 & $S$ & 6.15 & 165.21 & 20 & 33 & 1.49 & 0.008 & 0.950 \\
\hline 3 & 2 & $S$ & 12.05 & 163.36 & 23 & 83 & 2.88 & 0.051 & 0.877 \\
\hline 4 & 2 & $\mathrm{P}$ & 14.41 & 18.13 & 17 & 83 & 2.39 & 0.039 & 0.878 \\
\hline 5 & 1 & $S$ & 6.74 & 71.97 & 10 & 0 & 1.00 & 0.000 & - \\
\hline 6 & 1 & $\mathrm{P}$ & 17.55 & 34.32 & 20 & 50 & 1.72 & 0.025 & 0.850 \\
\hline 7 & 1 & $\mathrm{P}$ & 16.53 & 29.85 & 22 & 0 & 1.00 & 0.000 & - \\
\hline 8 & 1 & $\mathrm{P}$ & 20.76 & 53.00 & 22 & 67 & 1.84 & 0.053 & 0.786 \\
\hline 9 & 2 & $\mathrm{P}$ & 18.78 & 0.00 & 23 & 83 & 2.83 & 0.046 & 0.897 \\
\hline 10 & 1 & $\mathrm{P}$ & 30.61 & 65.82 & 22 & 83 & 2.96 & 0.038 & 0.915 \\
\hline 11 & 1 & $\mathrm{P}$ & 30.76 & 138.67 & 21 & 100 & 2.41 & 0.000 & 1.000 \\
\hline 12 & 1 & $\mathrm{P}$ & 23.28 & 71.84 & 22 & 50 & 1.77 & 0.091 & 0.446 \\
\hline 13 & 3 & $S$ & 26.67 & 147.84 & 18 & 83 & 2.47 & 0.046 & 0.859 \\
\hline 14 & 3 & $S$ & 27.80 & 143.12 & 20 & 100 & 2.35 & 0.050 & 0.892 \\
\hline 15 & 2 & $S$ & 42.70 & 131.79 & 21 & 100 & 3.03 & 0.056 & 0.878 \\
\hline 16 & 3 & $S$ & 40.55 & 90.85 & 22 & 83 & 2.65 & 0.030 & 0.928 \\
\hline 17 & 3 & $\mathrm{P}$ & 39.98 & 114.17 & 20 & 67 & 2.09 & 0.042 & 0.791 \\
\hline 18 & 3 & $S$ & 12.21 & 156.66 & 22 & 67 & 1.95 & 0.018 & 0.912 \\
\hline Mean & & & & & & 65.73 & 2.15 & 0.034 & 0.917 \\
\hline
\end{tabular}

Size, population size class based on the estimation of the number of flowering individuals (1, less than 100 individuals; 2, between 100 and 400 individuals; 3, more than 400 individuals); age, fragment age class (primary or secondary); conn, connectivity; env, local environment as assesed using the scores of the first DCA axis; $n$, number of sampled individuals for which more than four loci were scorable; PLP, percentage of polymorphic loci ( 0.95 criterion); $A_{\mathrm{R}^{\prime}}$ allelic richness corrected for small sample sizes; $H_{\mathrm{O}}$, the mean observed heterozygosity; and $F_{\mathrm{IS}}$, the weighted average inbreeding coefficient with correction for small sample sizes. Values are absent for population 5 and 8 since $F_{\text {IS }}$ could not be calculated.

and the Northwest African coast. It occurs widely on mildly acid to calcareous, freely draining and preferably moist soils (Taylor 1997). In our study area, G. urbanum is confined to deciduous woodlands.

Geum urbanum is an allohexaploid $(2 n=6 x=46)$ (Smedmark \& Eriksson 2002; Smedmark et al. 2003) with disomic inheritance (Arens et al. 2004). It is a perennial, pubescent herb with a short, thick rhizome. Flowering stems reach $70 \mathrm{~cm}$. The number of inflorescences varies between two and five. Hermaphrodite flowers secrete nectar and are visited by a range of insects. The species has a mixed breeding system, tending to autogamy due to autodeposition of pollen (Taylor 1997). Reproduction is mainly sexual and there is no persistent seed bank (Roberts 1986). A single flowering head produces $c .100$ achenes. Seeds are hairy and have a 5-7-mm long hook, facilitating exozoochorous seed dispersal (Grime et al. 1988).

\section{Study site and sample collection}

The study area is situated in the central part of Belgium (50 $0^{\circ} 1-54^{\prime} \mathrm{N}, 4^{\circ} 53-59^{\prime} \mathrm{E}$ ) between Diest, Tienen and Leuven and comprises a large river valley bordered by small hills. Altitude ranges from 33 to $85 \mathrm{~m}$ above sea level.

Jacquemyn et al. (2003) demonstrated considerable forest turnover in the study area during the last 200 years.
In the 18th and 19th centuries, deforestation rates were three to seven times larger than reforestation rates, resulting in an overall decrease of the forest cover in the study area. From the 20th century onwards, deforestation rates gradually decreased and new forests were continuously established. As a result, the landscape currently consists of a mosaic of forest fragments of different ages. The oldest, primary patches have most likely always been forested (Jacquemyn et al. 2001a, b). The secondary patches investigated are between 50 and 140 years old and were subjected to agricultural land use before reforestation. Geum urbanum is absent in successional patches younger than 50 years (Jacquemyn et al. 2003) in the study area.

In June 2005, 18 populations, equally distributed among primary and secondary forest patches, were selected at random from a larger number of populations in the studied area. Population sizes were determined by estimating the number of flowering individuals in a patch. Population sizes were assigned to three classes: small (between 0 and 100 flowering individuals), intermediate (between 100 and 400 flowering individuals) and large (more than 400 flowering individuals) (Table 1). In the smallest populations ( 5 and 8 in Table 1 ), as few as 20 individuals were found, whereas in the largest population (17), over 1000 individuals were estimated. 


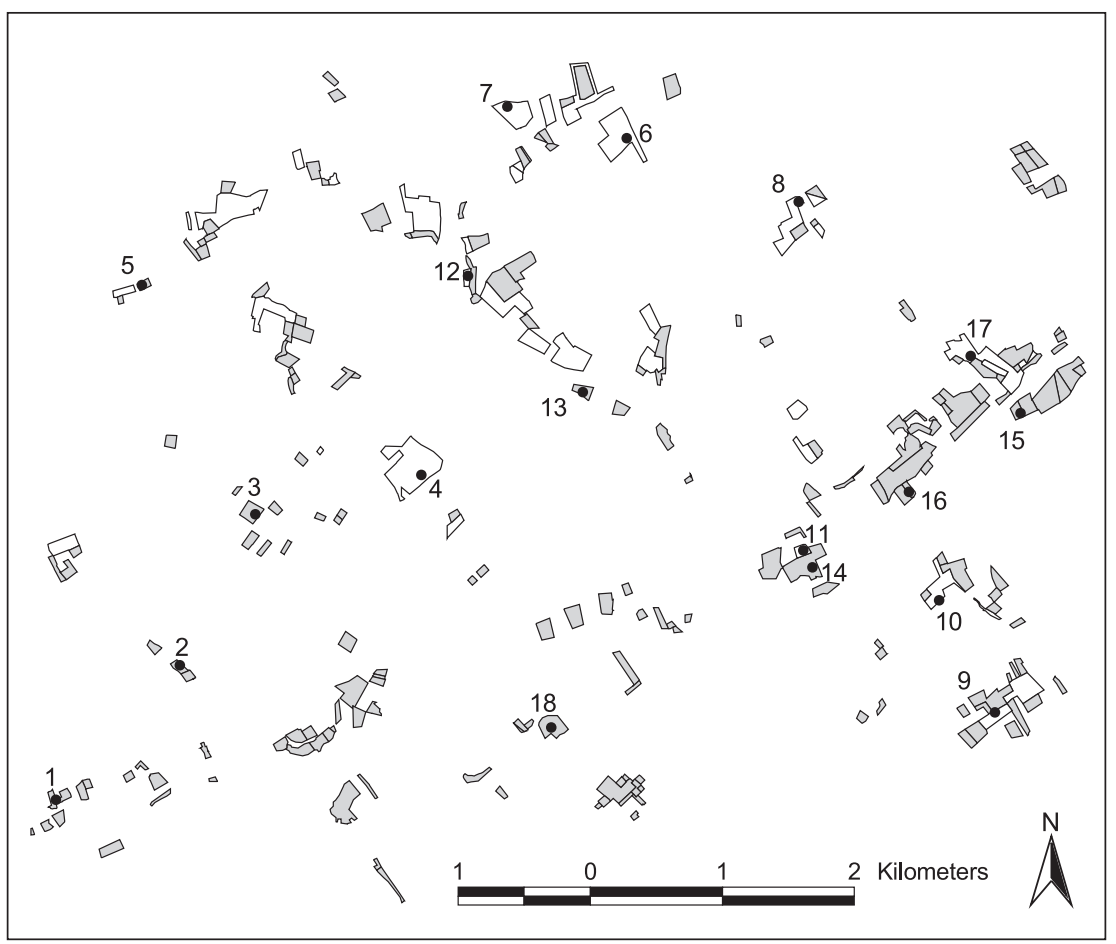

Fig. 1 Map of the studied region. Studied populations indicated by ID. Shaded polygons represent secondary-forest patches.

Populations in primary forest patches were classified as 'old' and, populations in secondary patches were classified as 'young' (Fig. 1). The herbaceous layer of each studied forest patch was characterized in spring and autumn 2000 by recording the presence or absence of forest plant species walking transects of several metres wide (a more detailed description is given in Jacquemyn et al. 2001b).

\section{Microsatellite analysis}

Between 20 and 23 individuals were sampled in each population for genetic analysis (Table 1). Plants that were evenly distributed within the area of the selected fragments were chosen for genetic analysis. From each individual, leaf material was collected, immediately frozen in liquid nitrogen and stored at $-80{ }^{\circ} \mathrm{C}$ before freeze-drying for $48 \mathrm{~h}$. Dried plant material was stored at room temperature under vacuum conditions until DNA extraction. Total plant DNA was extracted from $10 \mathrm{mg}$ of ground dried leaf material, using the DNeasy 96 Plant Kit (QIAGEN). DNA integrity and concentration were estimated on $1.5 \%(\mathrm{w} / \mathrm{v})$ agarose gels.

We used the microsatellite markers developed for G. urbanum by Arens et al. (2004). First, microsatellite primers were tested on a subsample of individuals from different populations. Six primer pairs, yielding consistent polymorphic patterns with a maximum number of two alleles per individual were selected to further genotype all samples. Microsatellite polymerase chain reaction (PCR) amplification was conducted in $10 \mu \mathrm{L}$ consisting of $2.5 \mathrm{ng}$ template DNA, $5 \mu \mathrm{L} 2 \times$ Multiplex PCR Mix (QIAGEN) and 1 pmol of each forward and reverse primer. All forward primers were fluorescently labelled (NED, FAM or HEX). In each PCR, three loci were amplified simultaneously. WGU2-28_HEX, WGU6-5_FAM and WGU6-7_NED were amplified in one reaction; WGU61_NED, WGU2-48_HEX, WGU2-10_FAM in another reaction. Simple sequence repeat (SSR) nomenclature follows Arens et al. (2004). Fragment separation and detection took place on an ABI PRISM 377 DNA sequencer on $36 \mathrm{~cm}$ denaturing gels using $4.25 \%$ polyacrylamide $(4.25 \%$ acrylamide/bisacrylamide 19/1, 6 M Urea in 1× TBE). In each lane, we loaded $0.25 \mu \mathrm{L}$ GeneScan-500 ROX labelled size standard (Applied Biosystems), $0.35 \mu \mathrm{L}$ loading dye (Applied Biosystems), $0.9 \mu \mathrm{L}$ Hidi Formamide and $1 \mu \mathrm{L}$ of PCR-product. Scoring of microsatellite patterns was performed in a semi-automated way using GENEMAPPER version 3.7 (Applied Biosystems).

\section{Data analysis}

Genetic diversity within populations. The following estimates of within-population genetic diversity were calculated using GENSURVEY (Vekemans \& Lefebvre 1997) and FSTAT 2.9.3.2 (Goudet 1995): allelic richness corrected for small sample sizes $\left(A_{\mathrm{R}}\right)$, the percentage of polymorphic loci $(P)$ and the weighted average inbreeding coefficient corrected for small sample sizes $\left(F_{\text {IS }}\right) . F_{\text {IS }}$ values were very large and not variable enough to accurately detect differences between populations (Table 1). Therefore, $F_{\text {IS }}$ was omitted from further statistical analysis. 
A stepwise generalized linear model (GLM) procedure was applied to select significant predictors of the genetic diversity measures. The explanatory variables included in the models were landscape connectivity, population size, fragment age group (old or young) and local environment. Connectivity of each patch to all other patches occupied by G. urbanum in the studied area was calculated according to Hanski (1994):

$$
S i=\sum_{j \neq i} \exp \left(-\alpha d_{i j}\right) A_{j}
$$

where $S i$ is the connectivity of patch $i$ (a patch is defined as a forest fragment containing G. urbanum), $d_{i j}$ is the distance between patches $i$ and $j$ and $A_{j}$ is the area of patch $j . \alpha$, a parameter scaling the effect of distance to migration ( $1 / \alpha$ is the average migration distance) was set to 1 (Moilanen \& Niemimen 2002). Other values for $\alpha$ yielded highly correlated results.

Local environment was quantified by the scores of forest patches on the first ordination axis resulting from a detrended correspondence analysis (DCA) of the vegetation data (McCune \& Mefford 1999). A preliminary ANOVA and Bonferonni test showed no significant differences in genetic diversity measures between population of size class 2 (between 100 and 400 individuals) and 3 (more than 400 individuals). Therefore, both classes were merged (class 1: $<100$ individuals; class $2: \geq 100$ individuals).

The stepwise GLM procedure alternated between forward and backward selection. The first variable included in the model was the most significant (significance was preliminary assessed by entering each variable solely in a model and ordering them by decreasing predictive power). Then the most significant of the remaining variables was added and the explanatory power of the GLM model was tested using Akaike's information criterion (AIC). At this step, nonsignificant variables, if found, were omitted. This process was repeated until the GLM was stable. For each genetic diversity measure, the model with the lowest AIC and containing only significant explanatory variables was selected. Finally, meaningful interaction terms of the selected predictive variables were examined for potential inclusion in the final models. Plots of fitted vs. residual values were used to check final models for departures from expected error distributions.

Preliminary analysis by means of chi-squared tests, Pearson's correlation and ANOvA indicated no significant correlation $(P$ values $>0.1)$ between connectivity and population size, connectivity and DCA-axis1, age class and DCA-axis1 or population size and DCA-axis1 $(P=0.173)$. Population size classes (two categories) and age groups were marginally correlated $(P=0.068)$. Absence of strong correlations allowed us to include all the variables as possible predictors in the model. All statistical analyses were performed using s-PLus 6.1 and spss 11.5 .

Genetic diversity among populations. Overall $F$-statistics (Weir \& Cockerham 1984) were calculated using an ANovA of gene frequencies as implemented in FSTAT 2.9.3.2 (Goudet 1995), which is assumed to perform better than Nei's estimates if sample sizes are smaller than 30 individuals (Berg \& Hamrick 1995). Confidence limits (95\%) were obtained through 10000 bootstraps over all loci and the significance of the differentiation for each locus assuming random mating was tested with the exact G-test (Goudet et al. 1996). Comparisons of genetic differentiation ( $\theta$, Weir \& Cockerham 1984) among groups of populations (grouped according to age or population size classes) were tested using 10000 permutations as implemented in FSTAT 2.9.3.2 (Goudet 1995). Mantel tests were carried out to check for the presence of isolation by distance and for effects of local environment on genetic differentiation. The matrices of pairwise geographical distances and herb-layer community similarity (calculated from presence/ absence data of forest plant species using the Dice coefficient) were correlated with the matrix of population pairwise genetic differentiation. Partial Mantel tests were used to analyse the same effects on genetic differentiation while holding the effect of the third matrix constant (Mantel \& Valand 1970). $P$ values and confidence intervals were obtained through random permutation of the columns of one matrix (10 000 permutations).

\section{Results}

\section{Genetic variation within populations}

The number of multilocus SSR genotypes per population varied between 1 and 17. For two of the smallest populations (populations 5 and 7), no polymorphism could be detected across the loci analysed. $P$ values varied between 0 and 100 and allelic richness varied between 1.00 and 3.03. The number of observed heterozygotes $H_{\mathrm{O}}$ was very low (0-0.09), resulting in extremely high estimates of inbreeding coefficients $\left(F_{\mathrm{IS}}\right)$ for all populations (Table 1$)$.

The GLM with population size, connectivity and their interaction was selected as the best model for all three genetic diversity measures, explaining $60.85 \%, 71.67 \%$ of the variance of $A_{\mathrm{R}}$ and $P$, respectively (Table 2). To further explore these results, we split up the data set according to population size and performed a regression analysis of connectivity against genetic diversity for the small and the large populations separately. Connectivity did not significantly affect the genetic diversity of large populations whereas it positively affected the genetic diversity of small populations (Table 3, Fig. 2). 
Table 2 Analysis of variance table of effects on within-population genetic diversity

\begin{tabular}{lcrr}
\hline Source & d.f. & \multicolumn{1}{c}{$P$} & \multicolumn{1}{c}{$A_{\mathrm{r}}$} \\
\hline Population size & 1 & $16.787 \dagger$ & $10.363+$ \\
Connectivity & 1 & $9.066+$ & $6.515^{*}$ \\
Connectivity $\times$ Population size & 1 & $9.565+$ & $4.886^{*}$
\end{tabular}

$F$ values and $P$ values estimates of the explanatory variables selected using a stepwise GLM procedure.

${ }^{*} P<0.05 ;+P<0.01$.

Table 3 Parameter estimates of the effects of connectivity on PLP and $A_{\mathrm{R}}$ according to population size

\begin{tabular}{|c|c|c|c|c|}
\hline Dependent & $n$ & Parameter & B & $t$ \\
\hline \multirow[t]{4}{*}{ PLP } & \multirow[t]{2}{*}{$<100$} & Constant & -12.356 & -0.661 \\
\hline & & Connectivity & 3.164 & $3.552^{*}$ \\
\hline & \multirow[t]{2}{*}{$\geq 100$} & Constant & 66.330 & $7.328^{*}$ \\
\hline & & Connectivity & 0.573 & 1.725 \\
\hline \multirow[t]{4}{*}{$A_{\mathrm{R}}$} & \multirow[t]{2}{*}{$<100$} & Constant & 0.760 & 2.058 \\
\hline & & Connectivity & 0.055 & $3.129 *$ \\
\hline & \multirow[t]{2}{*}{$\geq 100$} & Constant & 2.169 & $8.108^{*}$ \\
\hline & & Connectivity & 0.011 & 1.164 \\
\hline
\end{tabular}

Coefficient estimates (B), $t$ values $(t)$ and population size class $(n)$. ${ }^{*} P<0.05$.

Table 4 Overall $F$-statistics according to Weir \& Cockerham (1984)

\begin{tabular}{lrll}
\hline Locus & \multicolumn{1}{l}{ N } & $\theta$ & $f$ \\
\hline WGU2-28 & 2 & 0.359 & 0.850 \\
WGU6-5 & 8 & 0.459 & 0.919 \\
WGU6-7 & 21 & 0.403 & 0.910 \\
WGU6-1 & 4 & 0.522 & 0.867 \\
WGU2-48 & 6 & 0.430 & 0.862 \\
WGU2-10 & 7 & 0.462 & 0.848 \\
Mean & & 0.435 & 0.885 \\
95\% confidence limits & & $0.404-0.465$ & $0.856-0.905$ \\
\hline
\end{tabular}

$N$, number of alleles; $\theta$ and $f$ correspond, respectively, to $F_{\mathrm{ST}}$ and $F_{\text {IS. }} .95 \%$ confidence limits obtained after 10000 bootstraps.

\section{Genetic variation among populations}

Overall F-statistics showed little variation across loci (Table 4). Genetic differentiation $(\theta)$ was significant for all loci and for each individual locus $(P$ values $<0.001)$. The estimation of overall inbreeding $(f)$ was 0.885 .

Mantel tests showed no significant correlation between the logarithm of the geographical distances and the genetic distances either without (Mantel- $\mathrm{r}_{\mathrm{DIST}} \times_{\mathrm{FST}}$ : 0.162, $P=0.111$; Fig. 3a) or with (Mantel-r DIST $_{\text {FST.DICE }}=0.093$, $P=0.214)$ control for herb-layer community similarity.

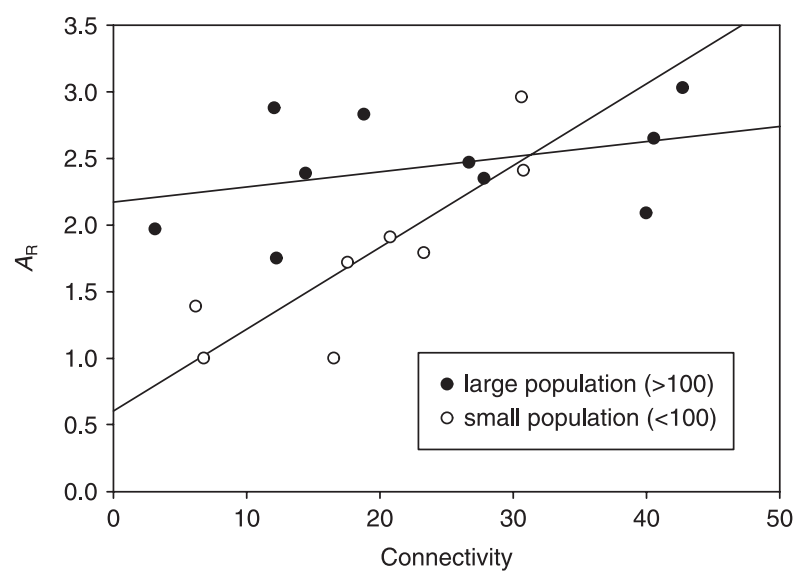

Fig. 2 Relationship between connectivity and genetic diversity $\left(A_{\mathrm{R}}\right)$ according to population size classes.
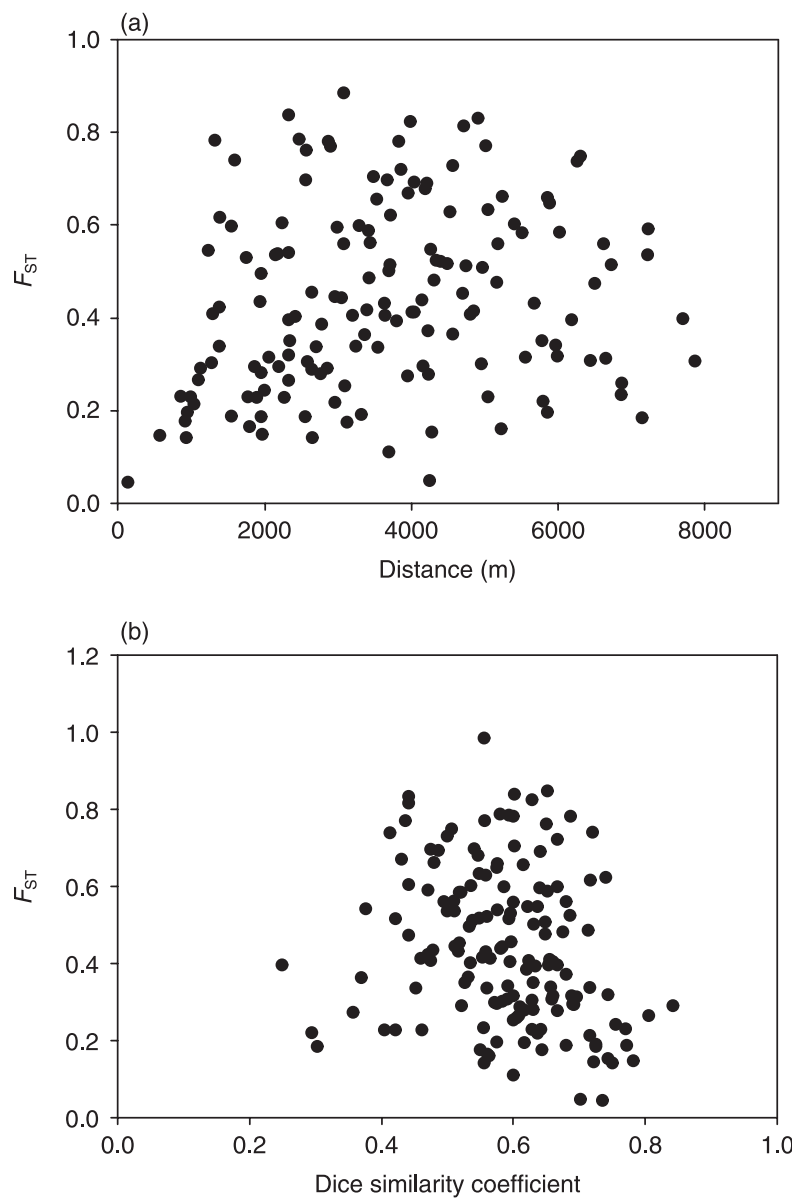

Fig. 3 Relationship between genetic differentiation ( $\theta$ ) and (a) geographical distance $(\mathrm{km}),(\mathrm{b})$ environment similarity (Dice coefficient).

Community similarity and population pairwise genetic distances were not significantly correlated before and after control for geographical distance (Mantel- $\mathrm{r}_{\text {DICE }}{ }{ }_{\mathrm{FST}}$ : $-0.228, P=0.101$; Mantel-r DICE FST. DIST $-0.188, P=0.133$; 
Fig. 3b). Between-population genetic differentiation was significantly higher for small populations $(<100$ individuals) than for large populations ( $\geq 100$ individuals) $\left(F_{\mathrm{ST}}\right.$ small: $0.715 ; F_{\mathrm{ST}}$ large: $\left.0.314 ; P=0.005\right)$. Pairwise population differentiation also differed among age groups, with old populations showing higher levels of genetic divergence among themselves than young populations; however, the effects of age on genetic differentiation were less pronounced than the effects of population size $\left(F_{\mathrm{ST}}\right.$ old: $0.608 ; F_{\text {ST }}$ young: $\left.0.395 ; P=0.044\right)$.

\section{Discussion}

\section{Overall genetic structure and gene flow}

Plant species with a selfing or mixed breeding system naturally tend to have higher levels of inbreeding and increased between-population genetic differentiation compared to obligate outcrossers (Hamrick \& Godt 1996). The high overall fixation index found in this study for Geum urbanum is consistent with this. Based on the morphological arrangements of the stamen and the stigma, Taylor (1997) suggested that the species is highly selfing. Our estimates are comparable with the $H_{\mathrm{O}}$ values reported by Arens et al. (2004) for G. urbanum populations sampled across Germany, Switzerland and Estonia. Average genetic differentiation estimates $(\theta: 0.435)$ and fixation index estimates $(f: 0.885)$ are also in agreement with average values obtained for mainly selfing species (Hamrick \& Godt 1996).

High seed set and the fact that seeds are hairy and have a long hook, facilitating exozoochorous seed dispersal (Grime et al. 1988), suggest that gene flow is primarily mediated by seed dispersal. We did not find a monotonically increasing isolation-by-distance relationship in the study area (Manel et al. 2003) (Fig. 3). Although some of adjacent populations showed lowered genetic differentiation, the pattern becomes more random as the distance increases. This suggests that mostly, seed flow among adjacent, well-connected patches and some long-distance seed flow determined the spatial genetic structure.

\section{Effects of habitat fragmentation}

Population size, landscape connectivity and their interaction strongly affect the genetic diversity of the studied populations. The significant slope of the regression line for small populations suggests that within-population genetic variation of small populations is more susceptible to isolation compared to large populations. The fact that small-sized populations were genetically more differentiated among themselves compared to large populations underpins the effects of random genetic drift in small populations. Although some long-distance seed flow seemed to be present, the fact that genetic diversity is affected by connectivity indicates that gene flow towards more isolated populations is restricted. The effects of connectivity are in agreement with a study of Jacquemyn et al. (2003) on distribution patterns of forest herbs in the same study area, showing that the distribution of G. urbanum was significantly related with landscape connectivity.

Small populations are expected to show reduced levels of genetic diversity and increased genetic divergence, especially when they are isolated, hampering the replenishment of lost alleles through gene flow (Young et al. 1996). The relationship between population size and genetic diversity in forest herbs has been shown in only a limited number of studies (e.g. Van Rossum et al. 2002; Culley \& Grubb 2003), and it has been suggested that small populations of forest herbs showing repeated seedling recruitment and short generation times are sensitive to genetic drift (Honnay et al. 2005). This has been confirmed in this study for G. urbanum, a species showing high seed set and recruitment rates in our study area (personal observation).

Interestingly, the positive effect of connectivity on genetic diversity was only apparent in populations with less than 100 individuals. Although it has been shown before that fragmentation erodes genetic variation through increased isolation and decreased population sizes (Young et al. 1996), the effect of their interaction has rarely been reported previously (but see Prober \& Brown 1994). We have clearly demonstrated that small populations are more prone to the effects of isolation relative to large populations. Most likely, reduced gene flow towards less connected fragments is insufficient to counteract the effects of genetic drift in small populations, preventing them from being 'rescued' from further genetic erosion and divergence (Richards 2000; Tallmon et al. 2004).

\section{Effects of local environment}

A number of studies using neutral genetic markers have demonstrated a significant influence of habitat type or local environment on the genetic diversity of plant populations (Odat et al. 2004; Jacquemyn et al. 2005). In this study, local environment did not primarily affect population genetic diversity, although a small influence of local environment through population size might have been present. In less suitable habitats, reduced seedling recruitment in concert with harsher selection may restrict population size and reduce the number of different genotypes in addition to the loss of alleles through genetic drift in small populations. We found no significant relationship between genetic divergence and habitat similarity, which further declined when controlling for 
the effects of geographical distances. Although we found no significant isolation by distance, inspection of Fig. 3 suggests that some adjacent populations (< approximately $1.2 \mathrm{~km}$ ) display reduced pairwise differentiation.

\section{Effects of fragment age}

Few studies have addressed the influence of fragment age on population genetic variation of forest herbs (Jacquemyn et al. 2004; Vellend 2004). Vellend (2004) showed reduced levels of genetic diversity and increased genetic divergence of secondary-forest populations of Trifolium grandiflorum relative to populations in primary forest. These differences were attributed to genetic bottlenecks at the time of founding. This was not the case in this study. Colonization during the last 90 years neither resulted in lower genetic variation, nor in increased genetic differentiation of the studied G. urbanum populations because of founder effects. Even though the studied populations are relatively isolated in a hostile landscape matrix, sufficient gene flow at the time of founding and afterwards, probably mediated by long- and shortdistance seed flow, must have prevented reflection of historical colonization events in the current population genetic structure.

In the migrant pool model (Whitlock \& McCauley 1990), genetic divergence only increases if the number of colonist is less than twice the number of migrants. Longdistance gene flow also might theoretically reduce the effects of founding (Le Corre \& Kremer 1998). Thus, a sufficient number of founding propagules combined with substantial long- and short-distance gene flow after the initial founding can explain the fact that age did not significantly affect genetic structure. Similar results, showing that colonization dynamics do not always increase genetic divergence and lower genetic diversity, have been reported by Jacquemyn et al. (2004, 2006). These authors found less differentiation between recently established populations of Primula elatior and Sisymbrium austriacum compared to old populations. Long-distance seed flow and a mixture of founding propagules originating from different populations, combined with recurrent extinction and colonization events in populations located in the immediate vicinity of the river prevented differentiation of newly founded $S$. austricum populations. Old (> 35 years) populations of $P$. elatior showed increased divergence, which was attributed to limited historical levels of gene flow.

In the case of G. urbanum, the higher differentiation of populations located in primary patches can most likely be attributed to a minor bias in the partitioning of population size over age classes, with smaller populations, which are more sensitive to loss of genetic diversity, located more often in primary forest patches.

\section{Acknowledgements}

This study was funded by grants of the Institute for the Promotion of Innovation through Science and Technology in Flanders (IWT-Vlaanderen) and the Flemish Fund for Scientific Research (FWO). We are grateful to Els Coart for helping with the sampling and scientific advice.

\section{References}

Antonovics J (1971) The effects of a heterogeneous environment on the genetics of natural populations. American Scientist, 59, 593-599.

Arens P, Durka W, Wernke-Lenting JH, Smulders MJM (2004) Isolation and characterisation of microsatellite loci in Geum urbanum (Rosaceae) and their transferability within the genus Geum. Molecular Ecology Notes, 4, 209-212.

Barrett SCH, Kohn J (1991) The genetic and evolutionary consequences of small population size in plant: implications for conservation. In: Genetics and Conservation of Rare Plants (eds Falk D, Holsinger KE), pp. 3-30. Oxford University Press, New York.

Berg EE, Hamrick JL (1995) Genetic structure of a turkey oak forest. Evolution, 49, 110-120.

Culley TM, Grubb TC (2003) Genetic effects of habitat fragmentation in Viola pubescens (Violaceae), a perennial herb with chasmogamous and cleistogamous flowers. Molecular Ecology, 12, 2919-2930.

Ellstrand NC, Elam DR (1993) Population genetic consequences of small population size: implications for plant conservation. Annual Review of Ecology and Systematics, 24, 217-242.

Giles BE, Goudet J (1997) A case study of genetic structure in a plant metapopulation. In: Metapopulation Biology (eds Hanski IA, Gilpin ME), pp. 429-454. Academic Press, New York.

Godt MJW, Johnson BR, Hamrick JL (1996) Genetic diversity and population size in four rare southern Appalachian plant species. Conservation Biology, 10, 796-805.

Goudet J (1995) FSTAT (version 1.2): a computer program to calculate F-statistics. Journal of Heredity, 86, 485-486.

Goudet J, Raymond M, De Meeus T, Rousset F (1996) Testing genetic differentiation in diploid populations. Genetics, 144, 1933-1940.

Gram WK, Sork VL (2001) Association between environmental and genetic heterogeneity in forest tree populations. Ecology, 82, 2012-1021.

Grime JP, Hodgson JG, Hunt R (1988) Comparative Plant Ecology: A Functional Approach to Common British Species. Unwin Hyman, London.

Hall MC, Willis JH (2006) Divergent selection on flowering time contributes to local adaptation in Mimulus guttatus populations. Evolution, 60 (2), 2466-2477.

Hamrick JL, Allard RW (1972) Microgeographical variation in allozyme frequencies in Avena habata. Proceedings of the National Academy of Sciences, USA, 69, 2100-2104.

Hamrick JL, Godt MJW (1996) Effects of life history traits on genetic diversity in plant species. Philosophical Transactions of the Royal Society of London. Series B, Biological Sciences, 351, 1291-1298.

Hanski I (1994) Patch occupancy dynamics in fragmented landscapes. Trends in Ecology \& Evolution, 9, 131-135.

Hanski I (1998) Metapopulation dynamics. Nature, 396, 41-49. 
Honnay O, Jacquemyn H, Bossuyt B, Hermy M (2005) Forest fragmentation effects on patch occupancy and population viability of herbaceous plant species. New Phytologist, 166, 723-734.

Jacquemyn H, Butaye J, Hermy M (2001a) Forest plant species richness in small, fragmented mixed deciduous forest patches: the role of area, time and dispersal limitation. Journal of Biogeography, 28, 801-812.

Jacquemyn H, Butaye J, Dumortier M, Hermy M, Lust N (2001b) Effects of age and distance on the composition of mixed deciduous forest fragments in an agricultural landscape. Journal of Vegetation Science, 12, 635-642.

Jacquemyn H, Butaye J, Hermy M (2003) Influence of environmental and spatial variables on regional distribution of forest herbs in a fragmented and changing landscape. Ecography, 26, 768-776.

Jacquemyn H, Honnay O, Galbusera P, Roldán-Ruiz I (2004) Genetic structure of the forest herb Primula elatior in a changing landscape. Molecular Ecology, 13, 211-219.

Jacquemyn H, Brys R, Honnay O, Hermy M, Roldán-Ruiz I (2005) Local forest environment largely affects below-ground growth, clonal diversity and fine-scale spatial genetic structure in the temperate deciduous forest herb Paris quadrifolia. Molecular Ecology, 14, 4479-4488.

Jacquemyn H, Honnay O, Van Looy K, Breyne P (2006) Spatiotemporal structure of genetic variation of a spreading plant metapopulation on dynamic riverbanks along the Meuse River. Heredity, 96 (6), 471-478.

Keller LF, Waller DM (2002) Inbreeding effects in wild populations. Trends in Ecology \& Evolution, 17, 230-241.

Le Corre V, Kremer A (1998) Cumulative effects of founding events during colonization on genetic diversity and differentiation in an island and stepping-stone model. Journal of Evolutionary Biology, 11, 495-512.

Manel S, Schwartz MK, Luikart G, Taberlet P (2003) Landscape genetics: combining landscape ecology and population genetics. Trends in Ecology \& Evolution, 18, 189-197.

Mantel N, Valand RS (1970) A technique of nonparametric multivariate analysis. Biometrics, 26, 547-558.

McCauley DE (1991) Genetic consequences of local population extinction and recolonization. Trends in Ecology \& Evolution, 6, $5-8$.

McCauley DE (1994) Contrasting the distribution of chloroplast DNA and allozyme polymorphism among local populations of Silene alba: implications for studies of gene flow in plants. Proceedings of the National Academy of Sciences, USA, 91, 8127-8134.

McCauley DE, Raveill J, Antonovics J (1995) Local founding events as determinants of genetic structure in a plant metapopulation. Heredity, 75, 630-636.

McCune B, Mefford MJ (1999) PC-ORD Multivariate analysis of ecological date. Version 4. MjMSoftware Design, Gleneden Beach, OR.

Moilanen A, Niemimen M (2002) Simple connectivity measures in spatial ecology. Ecology, 84, 1131-1145.

Odat N, Jetschke G, Hellwig FH (2004) Genetic diversity of Ranunculus acris L. (Ranunculaceae) populations in relation to species diversity and habitat type in grassland communities. Molecular Ecology, 13 (5), 1251-1257.

Owuor ED, Fahima T, Beharav A, Korol A, Nevo E (1999) RAPD divergence caused by microsite natural selection. Genetica, 105, 177-192.
Prober SM, Brown AHD (1994) Conservation of the grassy white box woodlands: population genetics and fragmentation of Eucalyptus albens. Conservation Biology, 8, 1003-1013.

Richards CM (2000) Inbreeding depression and genetic rescue in a plant metapopulation. The American Naturalist, 155, 383-394.

Roberts HA (1986) Seed persistence in soil and seasonal emergence in plant species from different habitats. Journal of Applied Ecology, 23, 639-656.

Slatkin M (1977) Gene flow and genetic drift in a species subject to frequent local extinctions. Theoretical Population Biology, 12, 253-262.

Slatkin M (1993) Isolation by distance in equilibrium and nonequilibrum populations. Evolution, 47, 264-279.

Smedmark JEE, Eriksson T (2002) Phylogenetic relationships of Geum (Rosaceae) and relatives inferred from the nrITS and trnL-trnF regions. Systematic Botany, 27 (2), 303.

Smedmark JEE, Eriksson T, Evans RC, Campbell CS (2003) Ancient allopolyploid speciation in geinae (Rosaceae): evidence from nuclear granule-bound starch synthase (GBSSI) gene sequences. Systematic Biology, 52 (3), 374-385.

Storfer A, Murphy MA, Evans JS et al. (2007) Putting the 'landscape' in landscape genetics. Heredity, 98, 128-142.

Tallmon DA, Luikart G, Waples RS (2004) The alluring simplicity and complex reality of genetic rescue. Trends in Ecology $\mathcal{E}$ Evolution, 19 (9), 489-496.

Taylor K (1997) Biological flora of the British Isles. Geum urbanum L. Journal of Ecology, 85, 705-720.

Van Rossum F, Echchgadda G, Szabadi I, Triest L (2002) Commonness and long-term survival in fragmented habitats: Primula elatior as a study case. Conservation Biology, 16, 1286-1295.

Vekemans X, Lefebvre C (1997) On the evolution of heavy metal tolerant populations in Armeria maritima: evidence from allozyme variation and reproductive barriers. Journal of Evolutionary Biology, 10, 175-191.

Vellend M (2004) Parallel effects of land-use history on species diversity and genetic diversity of forest herbs. Ecology, 85, 3043-3055.

Weir BS, Cockerham CC (1984) Estimating F-statistics for the analysis of population structure. Evolution, 38, 1358-1370.

Whitlock M, McCauley D (1990) Some population genetic consequences of colony formation and extinction: genetic correlations within founding groups. Evolution, 44, 1717-1724.

Wright S (1931) Evolution in Mendelian populations. Genetics, 16, 97-159.

Young A, Boyle T, Brown A (1996) The population genetic consequences of habitat fragmentation for plants. Trends in Ecology E Evolution, 11, 413-418.

Zangerl AR, Bazzaz FA (1984) Effects of short-term selection along environmental gradients on variation in populations of Amaranthus retroflexus and Abutilon theophrasti. Ecology, 65, 207217.

This study is part of Katrien Vandepitte's PhD thesis on the genetics and fitness of forest herbs in fragmented landscapes. Hans Jacquemyn is a post-doctoral researcher who is mainly interested in population genetics and demography of plants. Olivier Honnay is a professor with a research focus on plant conservation biology. Isabel Roldán-Ruiz is professor and senior scientist at ILVO, interested in molecular genetics. 